\title{
Induction of nitric oxide synthase activity in pulmonary arteries from normoxic and chronically hypoxic rats
}

\author{
C. Carville*, S. Adnot*, S. Eddahibi*, E. Teiger*, D. Rideau*, B. Raffestin**
}

Induction of nitric oxide synthase activity in pulmonary arteries from normoxic and chronically hypoxic rats. C. Carville, S. Adnot, S. Eddahibi, E. Teiger, D. Rideau, B. Raffestin. @ERS Journals Ltd 1997.

ABSTRACT: Chronic hypoxia has recently been shown to upregulate inducible nitric oxide synthase (iNOS) gene expression in rat lung. In the present study, we questioned whether induction of NO synthesis could alter the reactivity of pulmonary arteries (PA) from chronically hypoxic $(\mathrm{CH})$ rats.

Dose-response curves to phenylephrine (PE) $10^{-9}$ to $5 \times 10^{-6} \mathrm{M}$ ) were examined in $\mathrm{PA}$ rings as well as response to $\mathrm{L}$-arginine analogues in isolated lungs from $\mathrm{CH}$ or normoxic $(\mathbf{N})$ rats after various incubation times.

Although maximal contraction to $\mathrm{PE}$ did not differ in $\mathrm{PA}$ from $\mathrm{CH}$ rats compared to $\mathrm{N}$ rats at time $0(361 \pm 53$ vs $506 \pm 52 \mathrm{mg}$, respectively), it was markedly decreased after prolonged incubation $(149 \pm 28$ vs $386 \pm 47 \mathrm{mg}$, respectively, at $4 \mathrm{~h}$; $\mathbf{p}<\mathbf{0 . 0 0 1}$ ). This phenomenon persisted after endothelial-denudation, but was reversed by $\mathrm{N}^{\mathrm{G}}$-monomethyl-L-arginine (L-NMMA) $\left(5 \times 10^{-4} \mathrm{M}\right)$ and prevented by actinomycin $\mathrm{D}\left(2 \times 10^{-6} \mathrm{M}\right)$. In contrast, maximal contraction to $\mathrm{PE}$ in aorta from $\mathrm{CH}$ rats was similar at time 0 and $4 \mathrm{~h}$. After a short incubation, PA contraction to LNMMA was greater in $\mathrm{CH}$ than in $\mathrm{N}$ rats $(96 \pm 17$ vs $33 \pm 9 \mathrm{mg}$ at $90 \mathrm{~min} ; \mathrm{p}<0.05)$, was abolished after endothelial denudation, but persisted in $\mathrm{CH}$ rats in the presence of calmidazolium $\left(5 \times 10^{-4} \mathrm{M}\right)$. At $4 \mathrm{~h}$, contraction to L-NMMA was abolished in endothelium-denuded PA from $\mathrm{N}$ rats but only attenuated in those from $\mathbf{C H}$ rats. In salt solution perfused lungs, L-NMMA added 30 or 90 min after isolation did not alter baseline pressure in $\mathrm{N}$ rats but caused its increase in $\mathrm{CH}$ rats. Whereas iNOS messenger ribonucleic acid (mRNA) was detectable by reverse-transcriptase polymerase chain reaction in the PA wall of $\mathrm{N}$ or $\mathrm{CH}$ rats after $4 \mathrm{~h}$ of incubation, it was absent in both at the time of isolation. In contrast, there was evidence of iNOS mRNA in lungs from $\mathrm{CH}$ rats at the time of isolation but no signal in those from $\mathrm{N}$ rats.

In conclusion, there is induction of nitric oxide synthase activity in pulmonary arteries from normoxic and chronically hypoxic rats after prolonged incubation, but this effect is more pronounced in pulmonary arteries from chronically hypoxic rats.

Eur Respir J 1997; 10: 437-445.
*Département de physiologie, INSERM U296, Hôpital Henri Mondor, Créteil, France. **Departement de physiologie, Université Paris V, Hôpital Ambroise Paré, Boulogne, France.

Correspondence: S. Adnot Service des Explorations Fonctionnelles Hôpital Henri Mondor 94010 Créteil

France

Keywords: Arginine analogues endothelium-derived relaxing factor pulmonary circulation pulmonary vascular reactivity

Received: May 231996

Accepted after revision October 251996
In recent years, there has been considerable interest in the role of nitric oxide (NO) in the normal and remodelled pulmonary circulation. Endothelium-derived NO has been shown to play an important role not only in modulating the pulmonary vascular tone but also in the control of smooth muscle proliferation associated with vascular remodelling. Indeed, vasoconstrictor responses to various stimuli, such as acute hypoxia [1,2], angiotensin II [1] and endothelin-1 [3], are potentiated by inhibitors of NO synthesis. In rats exposed to chronic hypoxia, supplying NO to the pulmonary vessels by continuous inhalation attenuates muscularization of distal vessels [4]. More recently, NO has also been shown to inhibit gene expression of endothelin [5] and various growth factors, such as platelet-derived growth factor (PDGF) [5] and vascular endothelial growth factor (VEGF) [6].

In chronic hypoxic pulmonary hypertension, there are contradictory reports concerning endothelium-derived
NO. Endothelium-dependent relaxation has been found to be impaired in conduit pulmonary arteries (PA) from humans [7] and rats [8, 9] during chronic hypoxia. We also found that NO-mediated vasodilation in response to acetylcholine or ionophore is abolished in lungs from chronically hypoxic rats [3]. Contrasting with these results in favour of a loss of endothelium-derived NO, some studies have found maintained or even increased NOmediated vasodilator response [10, 11]. Furthermore, several groups have reported that NO synthesis inhibitors cause a large, gradually developing vasoconstrictor response in lungs and conduit PA from chronically hypoxic rats, suggesting increased basal release of NO in this condition $[12,13]$.

So far, three isoforms of NO synthase (NOS) have been identified [14]. Two of the isoforms, one expressed in neurons and the other in endothelial cells, are constitutive and dependent on the calcium/calmodulin complex. 
The third isoform, which can be induced by cytokines in many cells, such as macrophages and smooth muscle cells, is insensitive to change in intracellular free calcium and cannot be blocked by inhibitors of calmodulin. L-arginine analogues inhibit NO formation but are not specific for the constitutive NO synthase of endothelial cells (eNOS). In the lungs from chronically hypoxic rats, the level of messenger ribonucleic acid (mRNA) and protein for inducible NO synthase (iNOS) has been found to be increased compared with normoxic controls [15]. Thus, the paradoxical results between the lack of endothelium-dependent NO vasodilation and the high vasoconstrictor effect of NO synthesis inhibitors in PA and isolated lungs from chronically hypoxic rats led us to the hypothesis that basal NO could be released by an iNOS during pulmonary hypertension. Since we had previously observed that reactivity to phenylephrine of conduit PA isolated from chronically hypoxic rats decreases rapidly when incubation is prolonged, we questioned whether NO released through the iNOS pathway could explain this loss of contractile activity.

To investigate induction of NOS in PA and lungs isolated from rats exposed to chronic hypoxia, the effect of various incubation times on reactivity to phenylephrine of PA isolated from normoxic and chronically (4 week) hypoxic rats were compared. The effect of endothelium denudation, pretreatment with the NO synthesis inhibitor, $\mathrm{NG}^{\mathrm{G}}$-monomethyl-L-arginine (L-NMMA), or blockade of transcription by actinomycin $\mathrm{D}$ on this time-dependent loss of contractility was examined. In addition, the effect of L-NMMA on baseline pressure of isolated lungs after various duration of perfusion with salt solution were compared. Finally, reverse transcription polymerase chain reaction (RT-PCR) was used to detect mRNA for iNOS in the vessel wall and the lungs from normoxic and chronically hypoxic rats.

\section{Materials and methods}

\section{Chronic hypoxia}

Male Wistar rats, weighing 250-300 g at the start of the experiment, were randomly divided into two groups. One group of rats was exposed to chronic hypoxia for 4 weeks, another group was maintained at room air (control normoxic group). All hypoxic and normoxic rats were kept in the same room, with the same light/dark cycle. Rat chow and tap water were provided ad libitum. Rats were exposed to hypoxia (fraction of inspired oxygen $\left.\left(F_{\mathrm{I}, \mathrm{O}_{2}}\right) 10 \%\right)$ in a $500 \mathrm{~L}$ ventilated chamber (Flufrance apparatus, Cachan, France) as described previously [3]. To establish the hypoxic environment, the chamber was flushed with a mixture of room air and nitrogen and the gas recirculated. The chamber was monitored with an oxygen analyser (Model OA150; Servomex, Crowborough, UK). Carbon dioxide was removed by soda lime granules and excess humidity prevented by cooling of the recirculation circuit. Temperature within the chamber remained at $22-24^{\circ} \mathrm{C}$. The chamber was opened every other day for $1 \mathrm{~h}$ to clean the cages and supply food and water. Hypoxic rats were studied within $1 \mathrm{~h}$ of removal from the chamber.

\section{Isolated rings}

Rats were anaesthetized with pentobarbital, $40 \mathrm{mg}$ i.p. The chest was opened, and heparin sulphate (100 IU) was injected into the right ventricle. The heart and lungs were then removed en bloc. The extrapulmonary left and right branches of the pulmonary artery and thoracic aorta were isolated and placed in cold Earle's balanced salt solution of the following composition (in $\mathrm{mM}$ ): 116 $\mathrm{NaCl}, 4.7 \mathrm{KCl}, 19 \mathrm{NaHCO}_{3}, 0.83 \mathrm{MgSO}_{4}, 1.8 \mathrm{CaCl}_{2} \cdot 2 \mathrm{H}_{2} \mathrm{O}$, $1.04 \mathrm{NaH}_{2} \mathrm{PO}_{4}, 5.5$ glucose, with phenol red $\mathrm{Na}(0.11$ $\left.\mathrm{g} \cdot \mathrm{L}^{-1}\right)$ included as a $\mathrm{pH}$ indicator, meclofenamate $(3.2$ $\mu \mathrm{M})$ added to inhibit prostaglandin synthesis, and polymyxin $\mathrm{B}\left(10 \mathrm{mg} \cdot \mathrm{mL}^{-1}\right)$ to avoid contamination of the solution by lipopolysaccharide (LPS). After gentle removal of surrounding adventitia, rings $2-3 \mathrm{~mm}$ in length were cut. In some preparations, care was taken to avoid damage to the endothelium; in others, the endothelium was removed mechanically by inserting a nylon thread into the lumen and gently rubbing the endothelium.

Vessel rings were mounted horizontally between two steel stirrups in organ chambers containing $10 \mathrm{~mL}$ of the Earle's salt solution bubbled with $20 \% \mathrm{O}_{2}$ and $5 \%$ $\mathrm{CO}_{2}\left(37^{\circ} \mathrm{C}, \mathrm{pH} 7.4\right)$. At the start of the experiment, resting passive force was adjusted at $750 \mathrm{mg}$ for the pulmonary arterial and $1,500 \mathrm{mg}$ for the aortic rings. These values were determined in previous experiments to be the optimum resting force for vessels of similar size. This passive force was defined as zero, and all subsequent measurements are presented as active force generated above this baseline.

After a resting period (30 $\mathrm{min})$, during which tension was readjusted and the bath flushed, rings were exposed to $\mathrm{KCl}(50 \mathrm{mM})$. Following maximal contraction, the organ chamber was rinsed. The rings were then exposed to phenylephrine $\left(5 \times 10^{-6} \mathrm{M}\right)$. When the contraction stabilized, acetylcholine $\left(10^{-6} \mathrm{M}\right)$ was added. A relaxation in response to acetylcholine reaching at least 80 and $40 \%$ of phenylephrine contraction in PA from normoxic and hypoxic rats, respectively, was needed to assess the presence of a functional endothelium. Indeed, we have previously demonstrated that endothelium-dependent relaxation to acetylcholine is decreased in PA rings from chronically hypoxic rats (maximal relaxation reaching $47 \%$ of phenylephrine contraction compared with $89 \%$ in rings from normoxic rats) [8]. The failure of acetylcholine to induce relaxation of rubbed rings was taken as an indicator of endothelium removal. The organ chamber was then rinsed several times until return of tone to baseline. This step was the beginning of all experimental protocols (time 0 ).

Effect of various incubation periods on vascular reactivity to phenylephrine in aortic and $P A$ rings from normoxic and chronically hypoxic rats. After readjusting resting passive force at $750 \mathrm{mg}$, dose-response curves to phenylephrine $\left(5 \times 10^{-10}\right.$ to $\left.5 \times 10^{-6} \mathrm{M}\right)$ were repeated on the same pulmonary arterial endotheliumintact rings from normoxic or chronically hypoxic rats at various time-points during the protocol (time 0, 90 min and $4 \mathrm{~h}$ ). Following the third dose-response curve to phenylephrine (time $4 \mathrm{~h}$ ), the organ chamber was flushed several times until return of the vessel to its baseline tone. L-NMMA $\left(5 \times 10^{-4} \mathrm{M}\right)$ was then administered. 
After contraction had stabilized, a fourth dose-response curve to phenylephrine was performed in the presence of L-NMMA.

A similar protocol was performed in aortic endothelium-intact and in endothelium-denuded PA rings from chronically hypoxic rats.

Vascular reactivity to phenylephrine after various incubation periods was also tested in endothelium-intact PA rings from chronically hypoxic rats in the presence of actinomycin D, an inhibitor of transcription. Actinomycin $\mathrm{D}\left(2 \times 10^{-6} \mathrm{M}\right)$ or its vehicle alone was added in the bathing media at the beginning of the experiment.

Vasoconstrictor effect of L-NMMA on PA rings from normoxic and chronically hypoxic rats. In separate experiments, the contractile effect of L-NMMA $\left(5 \times 10^{-4} \mathrm{M}\right)$ on basal tone was also tested at time $0,90 \mathrm{~min}$ or $4 \mathrm{~h}$ of protocol on endothelium-intact or denuded PA rings from normoxic and hypoxic rats. Separate vessels were used at each time-point. Resting passive force was readjusted at $750 \mathrm{mg}$ before testing the effect of L-NMMA on basal tone. In some experiments, calmidazolium $(5 \times$ $10^{-4} \mathrm{M}$ ) (calmodulin inhibitor) which selectively impairs the constitutive nitric oxide synthase activity [16], was added to the organ bath just before L-NMMA was tested.

Effect of L-arginine on contractile response to phenylephrine of $P A$ rings from normoxic and chronically hypoxic rats. At the end of the resting period, after precontraction of endothelium-intact PA rings by phenylephrine $\left(10^{-6} \mathrm{M}\right)$, a dose-response curve to the precursor of $\mathrm{NO}$, L-arginine $\left(10^{-5}\right.$ to $\left.10^{-3} \mathrm{M}\right)$ was performed. In separate experiments, a similar protocol was performed $90 \mathrm{~min}$ after the resting period.

\section{Isolated lungs from normoxic and chronically hypoxic rats}

Rats were anaesthetized with sodium pentobarbital (40 mg i.p.). After tracheal cannulation, they were ventilated with warmed humidified gas $\left(95 \%\right.$ air $\left./ 5 \% \mathrm{CO}_{2}\right)$ at 60 breaths $\cdot \mathrm{min}^{-1}$ with an inspiratory pressure of 9 $\mathrm{cmH}_{2} \mathrm{O}$ and an expiratory pressure of $2.5 \mathrm{cmH}_{2} \mathrm{O}$. A median sternotomy was performed and 100 IU heparin administered through the right ventricle. Cannulae were inserted into the pulmonary artery and the left ventricle, and the heart and lung were suspended in a humidified chamber at $37^{\circ} \mathrm{C}$. The lung was perfused through the pulmonary arterial cannula with a peristaltic pump, at a constant flow of $0.05 \mathrm{~mL} \cdot \mathrm{g}^{-1}$ body weight $\cdot \mathrm{min}^{-1}$. The recirculated perfusate was Earle's balanced salt solution with Ficoll, (4 g.100 mL-1, (type 70; Sigma Chemical Co., St. Louis, MO, USA) and meclofenamate $(3.2 \mu \mathrm{M})$. The lung was first flushed with $20 \mathrm{~mL}$ of salt solution before recirculation with the perfusate (total volume $30 \mathrm{~mL}$ ) was initiated. Effluent perfusate was drained from the left ventricular cannula into a reservoir. Perfusate temperature was maintained at $38^{\circ} \mathrm{C}$. Mean perfusion pressure was measured from a side port of the pulmonary arterial line (P23 XL transducer; Gould, Ballainvilliers, France). The pulmonary venous pressure was assumed to be zero. Each lung preparation was used to study only one of the following procedures. After a 30 or 90 min incubation period, during which flow was maintained constant at $0.05 \mathrm{~mL} \cdot \mathrm{g}^{-1}$ body weight $\cdot \mathrm{min}^{-1}$, L-NMMA (5× $10^{-4} \mathrm{M}$ final concentration) was added in the perfusate reservoir.

Detection of iNOS mRNA in the lungs or the conduit $P A$ from normoxic and chronically hypoxic rats

Extrapulmonary branches of the pulmonary arteries from normoxic and chronically (4 week) hypoxic rats were taken as described above, rinsed with cold Earle's salt solution, blotted and immediately frozen in liquid nitrogen. In additional experiments, they were placed in $10 \mathrm{~mL}$ warmed $\left(37^{\circ} \mathrm{C}\right)$ sterile Earle's salt solution bubbled with $20 \% \quad \mathrm{O}_{2} / 5 \% \mathrm{CO}_{2}$ for $4 \mathrm{~h}$ before being frozen. Total ribonucleic acid (RNA) was extracted from PA of four rats in each group, following the method of Chomczynski and SACCHi [17]. Total RNA was also extracted from lungs removed from normoxic $(n=4)$ and chronically hypoxic rats $(n=4)$. On removal, lungs were rinsed with salt solution, blotted and immediately frozen.

RT and PCR were performed successively in a single tube using a single enzyme, rTth polymerase, which demonstrates RT activity of RNA to complementary deoxyribonucleic acid (cDNA) in the presence of $\mathrm{MnCl}_{2}$, and PCR of cDNA in the presence of $\mathrm{MgCl}_{2}$ (GeneAmp thermostable rTth reverse transcriptase RNA PCR kit; Perkin Elmer Norwalk, CT, USA). RT was performed at $65^{\circ} \mathrm{C}$ for $15 \mathrm{~min}$ in $20 \mu \mathrm{L}$ of buffer containing RNA (500 $\mathrm{ng}$ ), the enzyme (5 U), $\mathrm{MnCl}_{2}(1 \mathrm{mM})$, deoxynucleotides $(200 \mu \mathrm{M}$ of each), and oligonucleotides $(0.75 \mu \mathrm{M})$. PCR was started with the addition of $80 \mu \mathrm{L}$ of a mixture containing water, chelation buffer of $\mathrm{MnCl}_{2}$, and $\mathrm{MgCl}_{2}$ (1.5 $\mathrm{mM})$. The oligonucleotide primer sequences for iNOS, corresponding to the amino acid residues 1-8 and 265273 of the murine macrophage cells NOS 5'-region [18], were 5'ATGGCTTGCCCCTGGAAGTTTCTC3' (sense) and 5'CCTCTGATGGTGCCATCGGGCATCTG3' (antisense). PCR was carried out according to the following schedule: denaturation, annealling and elongation at 94, 65 , and $70^{\circ} \mathrm{C}$ for $1 \mathrm{~min}$ each, respectively, for 30 cycles. $\mathrm{P}^{32}$-labelled deoxycytidine triphosphate (32P-dCTP) was added $(0.3 \mu \mathrm{M}$ for each sample). A $3 \mu \mathrm{L}$ aliquot from each PCR reaction was electrophoresed in a polyacrylamide gel $(100 \mathrm{~V}$ for $1 \mathrm{~h})$ and the amplified products were visualized by autoradiography $\left(24-48 \mathrm{~h}\right.$ at $\left.-80^{\circ} \mathrm{C}\right)$.

The $\beta$-actin mRNA level, using Amprimer set for RTPCR (Clontech laboratories, CA, USA), was used as a control. The PCR products were electrophoresed on a $0.8 \%$ agarose gel containing ethidium bromide.

Drugs

Phenylephrine and acetylcholine were obtained from Sigma, and diluted in saline. Actinomycin D (Sigma) was diluted in ethanol, calmidazolium (Sigma) in dimethyl sulphoxide (DMSO), L-NMMA (Novabiochem) in distilled water, meclofenamate (Substantia, Orleans) in saline. All concentrations given are the final concentration. 


\section{Statistical analysis}

Results are given as mean \pm SEM. Two-way analysis of variance (ANOVA) with repeated measurements was performed to compare contractile response to phenylephrine at time 0 between PA from chronically hypoxic and normoxic rats, testing for group effect, dose of the vasoconstrictor agent, and interaction between group and dose. In the normoxic and chronically hypoxic groups, we also compared the effects of various incubation periods on the median effective dose (ED50) and maximal response of the dose-response curve to phenylephrine by one-way ANOVA with repeated measurements. When a significant difference was observed, comparisons between values after prolonged incubation versus values at time 0 were carried out with a Dunnett's test. Decrease of maximal response with time was compared between pulmonary arteries from chronically hypoxic and normoxic rats with a two-way ANOVA, testing for group effect, time, and interaction between group and time. Comparisons between groups were also performed with one-way Kruskal Wallis ANOVA or Mann Whitney nonparametric test. Differences were considered significant at p-values less than 0.05 .

\section{Results}

Effect of prolonged incubation on vascular reactivity to phenylephrine of pulmonary arterial rings from chronically hypoxic and normoxic rats

Contractile response to phenylephrine did not differ significantly in endothelium-intact PA rings from nor- moxic $(n=7)$ and chronically hypoxic rats $(n=12)$ when the dose-response curve was performed immediately after the resting period (time 0) (fig. 1).

Although there was no significant shift of ED50, there was a marked decrease of maximal contractile response in PA from chronically hypoxic rats when incubation of the rings was prolonged, maximal response to phenylephrine decreasing from $361 \pm 53 \mathrm{mg}$ at time 0 to $257 \pm$ 40 and $149 \pm 28 \mathrm{mg}$ at $90 \mathrm{~min}$ and $4 \mathrm{~h}$, respectively $(\mathrm{p}<$ 0.05 and $\mathrm{p}<0.01$ ). A decrease of maximal response with time was also observed in PA from normoxic rats, but was less pronounced than in chronically hypoxic rats. In PA from normoxic rats, maximal responses at 0 and 90 min did not differ significantly, being $506 \pm 57$ and $447 \pm$ $70 \mathrm{mg}$, respectively. Hyporeactivity was observed only on the third dose-response curve repeated $4 \mathrm{~h}$ after the first one, with the maximal response reaching $386 \pm 47$ $\mathrm{mg}(\mathrm{p}<0.05)$.

After prolonged incubation, the NO synthesis inhibitor, L-NMMA, restored contraction to phenylephrine in PA rings from chronically hypoxic rats. In rings from normoxic rats, addition of L-NMMA after $4 \mathrm{~h}$ of incubation caused a potentiation of contraction when compared with baseline contraction at time $0(\mathrm{p}<0.01)$ (fig. 2$)$.

Although less marked, the decrease of responsiveness to phenylephrine with prolonged incubation was also observed in endothelium-denuded PA from chronically hypoxic rats, maximal response to phenylephrine decreasing from $438 \pm 50$ at 0 to $331 \pm 55 \mathrm{mg}$ and $278 \pm 52 \mathrm{mg}$ at 90 min and $4 \mathrm{~h}$, respectively $(\mathrm{p}<0.05$ and $\mathrm{p}<0.01)(\mathrm{n}=8)$ (fig. 3). Again contraction was restored in the presence of L-NMMA.

Loss of responsiveness after prolonged incubation of endothelium-intact PA from chronically hypoxic rats was completely prevented by addition of actinomycin $\mathrm{D}(\mathrm{n}=$ 8 ) in the bathing media (fig. 4). a)

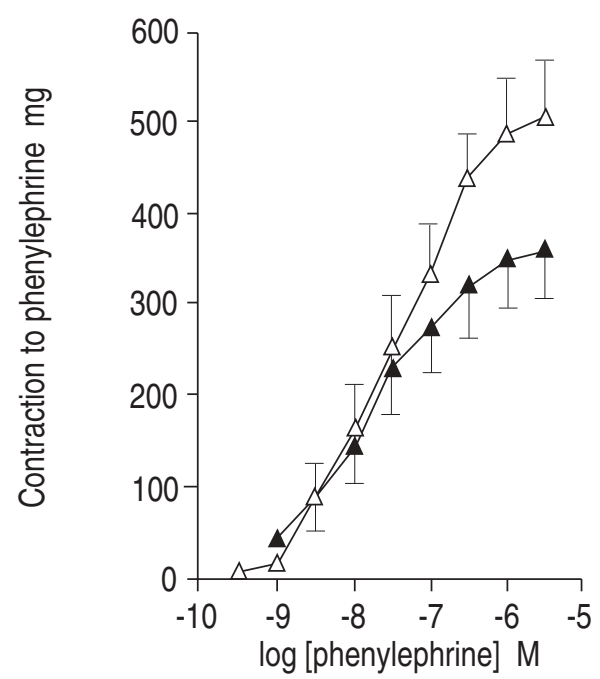

b)

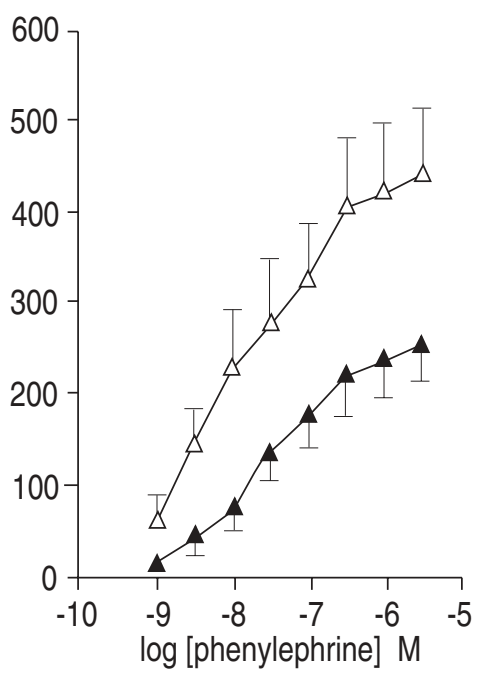

c)

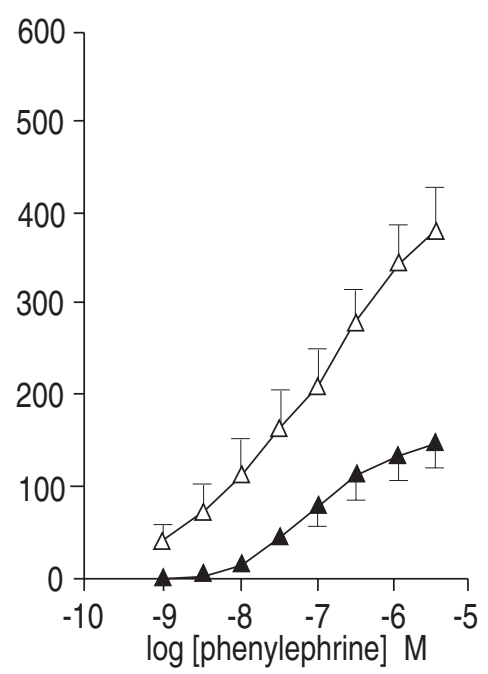

Fig. 1. - Dose-response curves to phenylephrine in pulmonary arteries (PA) from normoxic $(-\Delta-)$ ( -7$)$ and chronically hypoxic rats $(-\Delta-)(\mathrm{n}=12)$. a) Contraction to phenylephrine was elicited 30-45 min after isolating the vessel (time 0 of protocol; and repeated b) 90 min; and c) $4 \mathrm{~h}$ after the first dose-response curve. Values are presented as mean \pm sEM. Dose-response curves of normoxic and chronically hypoxic rats did not differ significantly at time 0 (two-way analysis of variance (ANOVA) with repeated measurements). The maximal response in rings from chronically hypoxic rats decreased significantly at $90 \mathrm{~min}$ and $4 \mathrm{~h}$, as compared to the initial value at time 0 (p<0.05 and p $<0.01$, respectively, Dunnett's test after ANOVA with repeated measurements). The maximal response in rings from normoxic rats was significantly decreased at time $4 \mathrm{~h}(\mathrm{p}<0.05$, Dunnett's test). There was no significant change of median effective dose (ED50) with time in the two groups of rats. 

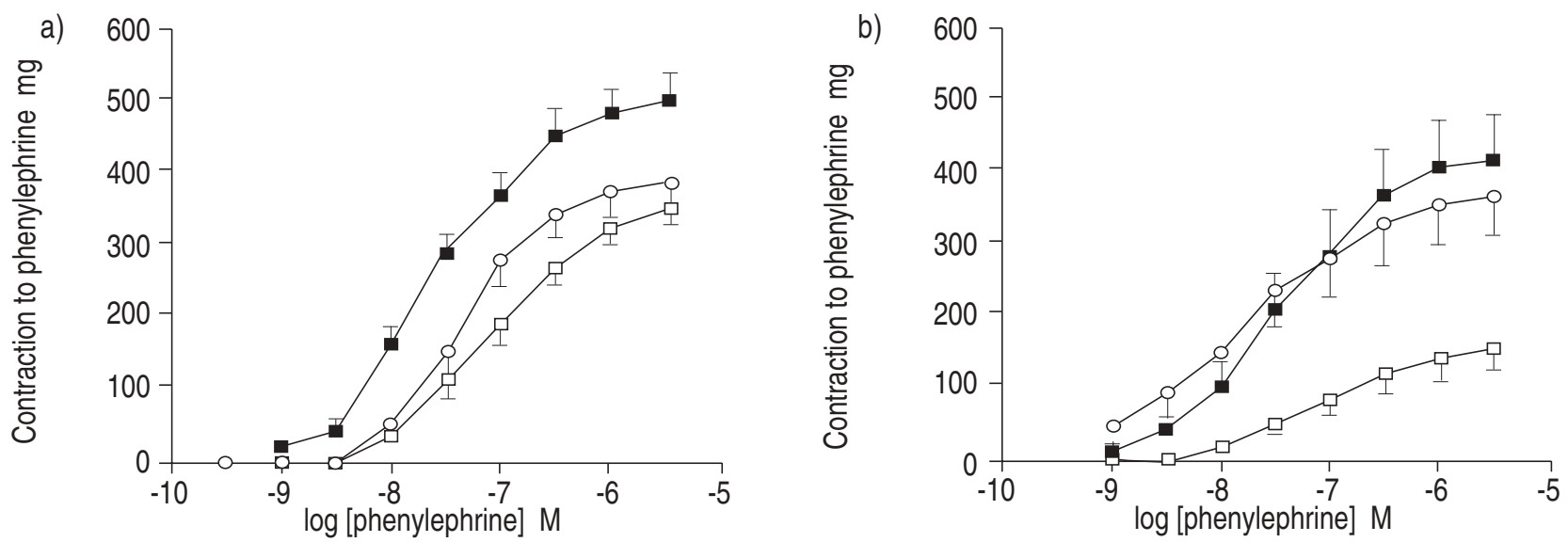

Fig. 2. - Effect of pretreatment with $\mathrm{N}^{\mathrm{G}}$-monomethyl-L-arginine (L-NMMA) $\left(5 \times 10^{-4} \mathrm{M}\right)$ on dose-response curves to phenylephrine in pulmonary arteries (PA) from: a) normoxic ( $\mathrm{n}=10)$; and $\mathrm{b})$ chronically hypoxic rats $(\mathrm{n}=11)$. L-NMMA was added to the organ bath following the third doseresponse curve performed at $4 \mathrm{~h}$ of protocol. Values are presented as meantsem. After L-NMMA, the contractile response to phenylephrine was restored in PA from chronically hypoxic rats and potentiated in rings from normoxic animals $(\mathrm{p}<0.01$, time $4 \mathrm{~h}+\mathrm{L}-\mathrm{NMMA}$ as compared to the first dose-response curve performed at time 0). ——_ : time 0 ; —ـ—: time $4 \mathrm{~h}$; ———: time $4 \mathrm{~h}+\mathrm{L}-\mathrm{NMMA}$.

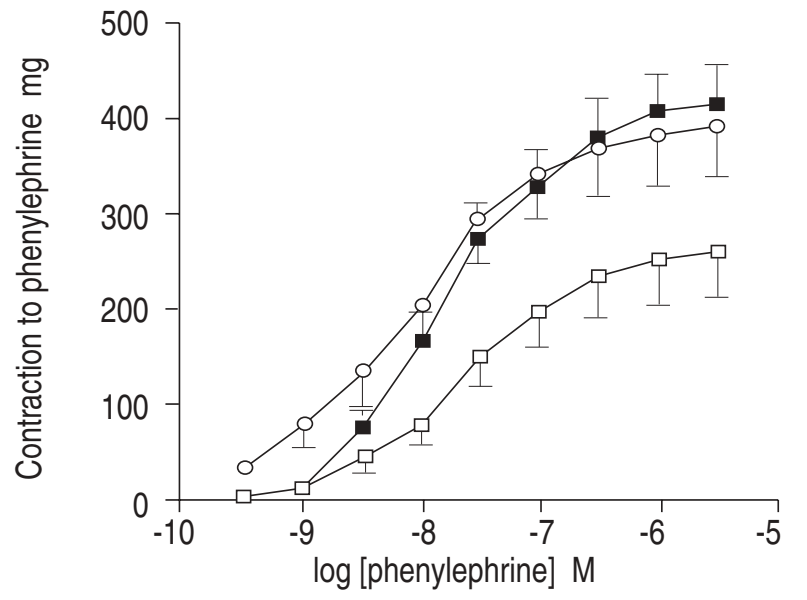

Fig. 3. - Dose response curves to phenylephrine in pulmonary arteries (PA) from chronically hypoxic rats without endothelium $(n=8)$. There was a significant decrease of maximal response after prolonged incubation as compared to time $0(\mathrm{p}<0.05$ at time $90 \mathrm{~min}, \mathrm{p}<0.05$ at time $4 \mathrm{~h}$; Dunnett's test). For clarity, data at $90 \mathrm{~min}$ are not shown. Loss of responsiveness with time was reversed by treatment with $\mathrm{N}^{\mathrm{G}_{-}}$ monomethyl-L-arginine (L-NMMA) $\left(5 \times 10^{-4} \mathrm{M}\right)$. — $-\mathrm{O}$ - time 0 ; $\longrightarrow$ -

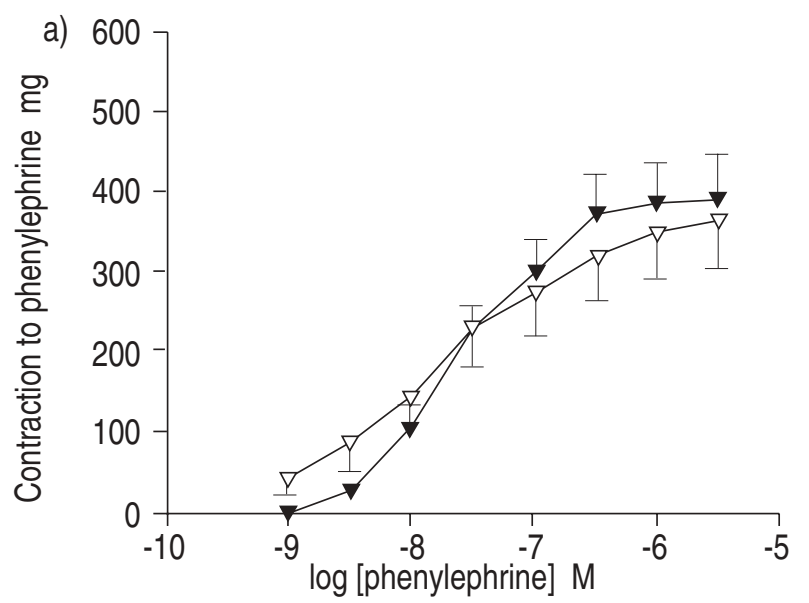

Effect of L-NMMA $\left(5 \times 10^{-4} \mathrm{M}\right)$ on baseline tone of PA rings from normoxic and chronically hypoxic rats

In PA from normoxic rats, at time 0 or $90 \mathrm{~min}$, LNMMA elicited a modest contraction. Contraction tended to be larger when L-NMMA was added after $4 \mathrm{~h}$ of incubation (fig. 5). In PA from hypoxic rats, the magnitudes of contraction elicited by L-NMMA at time 0 , 90 min or $4 \mathrm{~h}$ of protocol did not differ significantly. Contraction to L-NMMA also tended to be larger in PA from hypoxic rats than in rings from normoxic animals, the difference reaching significance when L-NMMA was added at $90 \mathrm{~min}(\mathrm{p}<0.05)$. Whereas in endothelial-denuded PA from chronically hypoxic rats the contraction elicited by L-NMMA at time 0 was abolished, it was only attenuated $(88 \pm 14 \mathrm{mg} ; \mathrm{n}=6)$ when L-NMMA was added after $4 \mathrm{~h}$ of incubation $(\mathrm{p}<0.05$ when compared with contraction in presence of endothelium). In contrast, contraction caused by L-NMMA after $4 \mathrm{~h}$ of incubation was abolished in endothelium-denuded PA from normoxic rats.

Calmidazolium, which completely abolished endothelium-dependent relaxation to acetylcholine of PA from

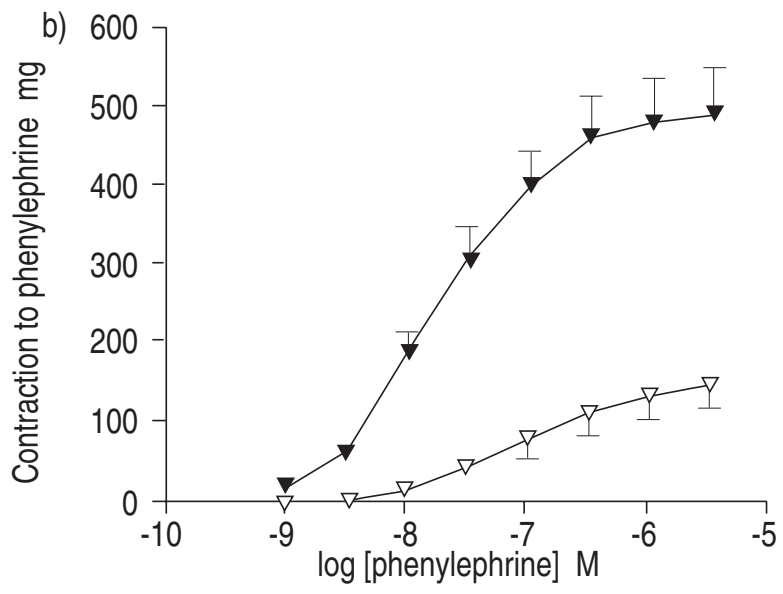

Fig. 4. - Dose response curves to phenylephrine of endothelium-intact pulmonary arteries (PA) from chronically hypoxic rats after pretreatment with actinomycin D $\left(2 \times 10^{-6} \mathrm{M}\right)(-\nabla-)(\mathrm{n}=8)$ or its vehicle $(-\nabla-)(\mathrm{n}=12)$. Dose response curves were repeated at time 0 , 90 min and $4 \mathrm{~h}$. For clarity, data at $90 \mathrm{~min}$ are not shown. a) time 0 ; b) time $4 \mathrm{~h}$. Values are presented as mean \pm sem. Actinomycin D completely prevented loss of responsiveness with time. 


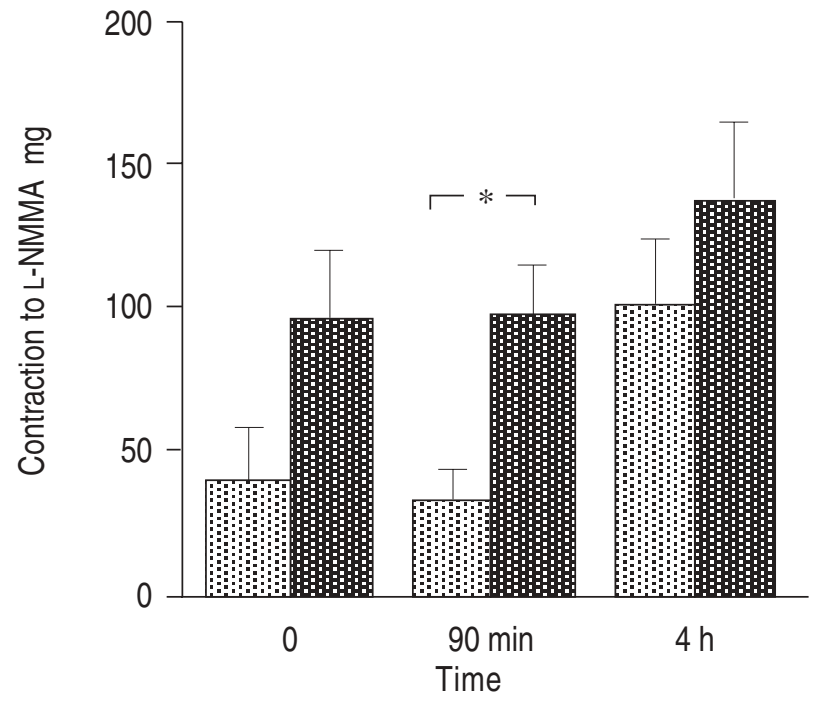

Fig. 5. - Effect of $\mathrm{N}^{\mathrm{G}}$-monomethly-L-arginine (L-NMMA) $\left(5 \times 10^{-4}\right.$ $\mathrm{M})$ on baseline tone of endothelium-intact pulmonary arterial (PA) rings from normoxic (E:B: ) and chronically hypoxic ( NMMA was added at time $0,90 \mathrm{~min}$ or $4 \mathrm{~h}$ of protocol. Values are presented as mean \pm SEM. Contraction to L-NMMA increased with time of incubation in PA from normoxic rats $(\mathrm{p}<0.05$, Kruskal-Wallis analysis of variance (ANOVA)). Contraction elicited by L-NMMA at 90 min was significantly larger in PA from chronically hypoxic rats than in rings from normoxic animals $(\mathrm{p}<0.05$, Mann-Whitney test). $*$ : $\mathrm{p}<0.05$.

normoxic rats (data not shown), did not alter contraction evoked by L-NMMA at time 0 in endothelium-intact PA rings from hypoxic rats $(164 \pm 44 \mathrm{mg}(\mathrm{n}=6)$ versus $80 \pm 17 \mathrm{mg}(\mathrm{n}=5)$ after calmidazolium or its vehicle, respectively; NS).

Effect of prolonged incubation on vascular reactivity to phenylephrine in aortic rings from chronically hypoxic rats

The dose-response curve to phenylephrine of endothelium-intact aortic rings from chronically hypoxic rats remained unchanged after prolonged incubation, maximal contraction being $3 \pm 0.4$ vs $3 \pm 0.5 \mathrm{~g}$ at time 0 and 4 $h$, respectively $(n=7)$.

Effect of L-arginine on contractile response to phenylephrine of endothelium-intact PA rings from normoxic and chronically hypoxic rats

At time 0, L-arginine failed to induce any relaxation of phenylephrine contracted PA rings from normoxic and chronically hypoxic rats. In contrast, at time $90 \mathrm{~min}$, $\mathrm{L}$-arginine caused a dose-dependent relaxation of phenylephrine contracted PA rings from chronically hypoxic rats $(n=10)$, but remained without effect on PA rings from normoxic rats $(n=7)$ (fig. 6). D-arginine was without effect (data not shown).

Effect of L-NMMA on baseline pressure of isolated lungs from normoxic and chronically hypoxic rats

L-NMMA added either 30 or $90 \mathrm{~min}$ after isolating the lungs from normoxic rats $(n=4$ of each) did not alter baseline pressure.

In lungs from chronically hypoxic rats, L-NMMA added at $30 \mathrm{~min}(\mathrm{n}=4)$ elicited an increase in baseline

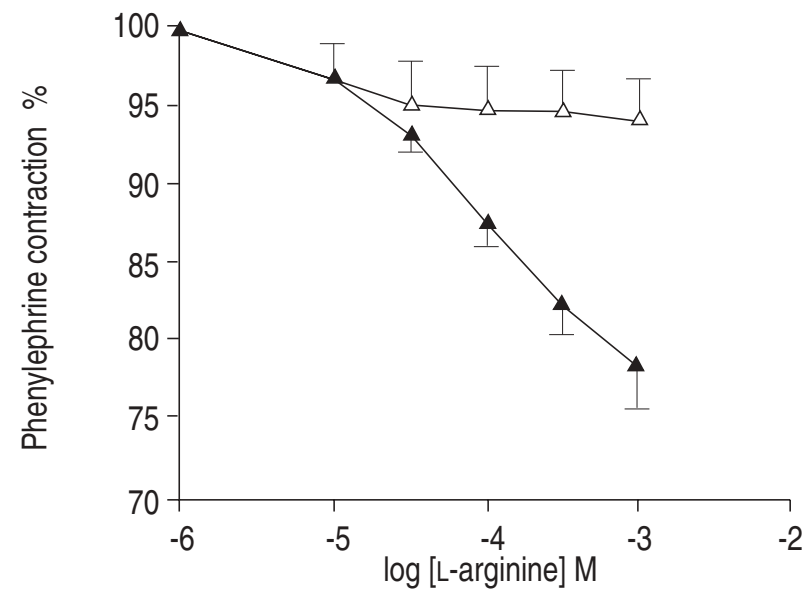

Fig. 6. - Dose-response curves to L-arginine performed at $90 \mathrm{~min}$ of protocol on contraction to phenylephrine $\left(10^{-6} \mathrm{M}\right)$ of endotheliumintact pulmonary arteries (PA) from normoxic $(-\Delta-)(n=7)$ and chronically hypoxic $(-\boldsymbol{-}-)(\mathrm{n}=10)$ rats. Values are presented as mean \pm SEM. L-arginine caused a dose-dependent relaxation in rings from chronically hypoxic rats but remained without significant effect on those from normoxic rats.

\section{$\begin{array}{lllllll}1 & 2 & 3 & 4 & 5 & 6 & M W\end{array}$}

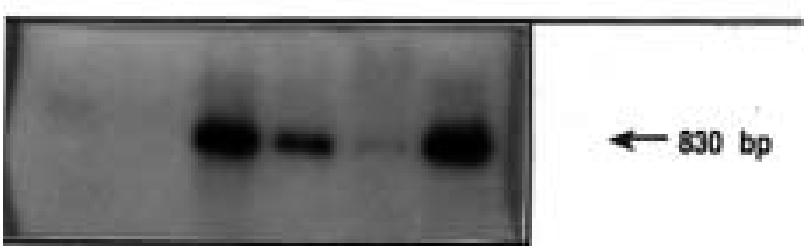

Fig. 7. - Gel photograph of reverse transcriptase polymerase chain reaction (RT-PCR) amplified inducible nitric oxide synthase (iNOS) complementary deoxyribonucleic acid (cDNA) derived from iNOS messenger ribonucleic acid (mRNA). No product was detected in the pulmonary artery (PA) wall of either normoxic (lane 1) or chronically hypoxic rats (lane 2) when the vessels had not been previously incubated. An amplified band of 830 base pairs (bp) was detected in the PA both of normoxic (lane 3 ) and chronically hypoxic rats (lane 4) after $4 \mathrm{~h}$ of incubation. No signal was detected in the lung from normoxic rats (lane 5), whereas it was present in the lung from chronically hypoxic rats (lane 6). Arrow: expected PCR product size.

pressure, reaching $2.9 \pm 0.4 \mathrm{mmHg}$ (range $2-3.7 \mathrm{mmHg}$ ) at $10 \mathrm{~min}$. When L-NMMA was added after $90 \mathrm{~min}$ of incubation $(n=4)$, the increase in baseline pressure reached $6.1 \pm 0.4 \mathrm{mmHg}$ at $10 \mathrm{~min}$ (range $5-7 \mathrm{mmHg}$ ).

Detection of iNOS MRNA in the pulmonary arterial wall and lungs from normoxic and chronically hypoxic rats

Immediately after isolation, iNOS mRNA was absent in arterial tissue from normoxic and chronically (4 week) hypoxic rats, but was present in both groups of rats after $4 \mathrm{~h}$ of incubation of the arteries (fig. 7). The $\beta$-actin mRNA level did not appear different in the PA wall from both groups. Inducible NOS mRNA was present in the lungs from chronically hypoxic rats, whereas it was absent in normoxic animals.

\section{Discussion}

In this series of experiments, we have provided evidence, for the first time, of increased NO production from an extraendothelial site in isolated PA from rats exposed 
to chronic hypoxia. This study shows that, in contrast to vessels from normoxic animals, phenylephrine-evoked contraction decreases rapidly with time of incubation in PA isolated from rats exposed to chronic hypoxia. This phenomenon was related to induction of NOS, since it was observed whether the endothelium was present or not, was corrected by addition of the NO synthesis inhibitor, L-NMMA, and was prevented by pretreatment with the transcription inhibitor, actinomycin D. Whereas prolonged in vitro incubation was necessary to detect iNOS mRNA in the PA wall both from normoxic and chronically hypoxic animals, there was evidence of iNOS mRNA in lungs from chronically hypoxic rats at the time of isolation.

In PA isolated from normoxic and hypoxic rats, a similar contractile response to phenylephrine was observed at the beginning of incubation. The noteworthy finding was the much more rapid decrease in contractile response of the vessels from chronically hypoxic rats when incubation was prolonged. Since all the experiments were conducted in the presence of meclofenamate, a cyclooxygenase inhibitor, we can rule out a role for cyclooxygenase products in this decrease. It was most likely to be related to an increased NO production, since LNMMA, a competitive inhibitor of the formation of NO, restored contractility. The fact that a decrease in contractile response was also observed in endotheliumdenuded PA from chronically hypoxic rat and similarly reversed by L-NMMA is consistent with some NO production situated outside of the endothelium in these vessels.

Constrictor response to L-NMMA was enhanced in PA from chronically hypoxic rats as compared to vessels from normoxic animals. Previous studies have also demonstrated that inhibition of NO synthase with various arginine analogues caused an enhanced vasoconstrictor effect in isolated PA and lungs from chronically hypoxic rats $[12,13]$. In the present study, constriction to L-NMMA was abolished by endothelial denudation when the time of incubation was short. This suggests that, at this time, baseline NO was released predominantly by the endothelium. However, this increase in tone elicited by L-NMMA in PA from chronically hypoxic rats was not affected by pretreatment with calmidazolium, an inhibitor of calmodulin, which has previously been demonstrated to impair the action of the constitutive NOS both on the development of relaxation and the production of cyclic guanosine monophosphate (cGMP), without affecting that mediated by the inducible enzyme [16]. These results indicate that activation of the calciumcalmodulin complex was not necessary for the basal release of NO by endothelial cells in PA isolated from chronically hypoxic rats. It is, therefore, likely that unstimulated basal production of NO in these vessels was due mainly to iNOS, which was at this time predominant in the endothelial cells. These results are consistent with previous data demonstrating induction of NOS both in endothelial and smooth muscle cell layers of PA from rats treated with endotoxin [19].

After a more prolonged incubation, L-NMMA elicited a contraction in PA from chronically hypoxic rats, which persisted after endothelial denudation, suggesting that, at this time, iNOS was also present in smooth muscle cells. In contrast, endothelial denudation abolished L-NMMA evoked contraction observed in PA from normoxic rats after prolonged incubation. This suggests that, after $4 \mathrm{~h}$ of incubation, NOS was still confined to the endothelium in these normotensive vessels. We cannot rule out that, despite addition of polymyxin B in salt solution, some endotoxin contamination could account for the induction of NOS and secondary depressed contractility after $4 \mathrm{~h}$ of incubation. However, since preparation of the salt solution and the experimental set-up were similar for PA from normoxic and chronically hypoxic rats, this cannot explain the functional differences observed between the two groups of animals.

After $90 \mathrm{~min}$ of incubation, L-arginine caused dosedependent relaxation of PA exclusively from chronically hypoxic rats. This is also consistent with induction of NOS in these vessels. Indeed, according to previous studies, activity of the inducible enzyme is limited by the supply of extracellular L-arginine, in contrast to activity of the constitutive enzyme, which is not rate-limited by the concentration of the endogenous amino acid in endothelial cells [20].

The vasoconstriction elicited after prolonged incubation by an inhibitor of NO synthesis in PA from rats exposed to chronic hypoxia, was observed not only in the conduit PA used in the ring studies but also in the smaller vessels investigated in the isolated lung preparations. In lungs from normoxic rats, L-NMMA added either 30 or $90 \mathrm{~min}$ after isolating the lungs did not affect baseline tone. In contrast, L-NMMA caused a pressor effect, which was more marked when this L-arginine analogue was added $90 \mathrm{~min}$ after isolation. Similar results were described by OKA et al. [13], when addition of $\mathrm{N}^{\omega}$-nitro-L arginine $90 \mathrm{~min}$ after isolating the lung, produced gradual development of a pressor response in lungs from high altitude but not low altitude rats. These results are also consistent with the increased release of NO decomposition products in the effluent of isolated lungs from rats exposed to hypobaric hypoxia, which has been reported previously [11].

Parallel studies in the thoracic aorta indicated that these changes were specific to the pulmonary vessels. We observed no decrease of reactivity to phenylephrine in the aorta from chronically hypoxic rats when incubation was prolonged up to $4 \mathrm{~h}$.

In addition to these functional studies, gene expression for iNOS in the PA wall from normoxic and chronically hypoxic rats was examined. Whereas, immediately after isolation, amplification by RT-PCR did not detect iNOS mRNA in vessels from either group of rats, iNOS mRNA was present in PA from both groups of rats after $4 \mathrm{~h}$ of incubation. Detection of the mRNA for iNOS in the wall of conduit PA after prolonged incubation was not specific to vessels from $\mathrm{CH}$ rats. Although our RT-PCR was not quantitative, we were unable to demonstrate a larger signal for iNOS in PA from $\mathrm{CH}$ rats as compared with the vessels from normoxics. However, detection of iNOS mRNA in lungs isolated from chronically hypoxic rats but not in those from normoxic rats lends further support for the induction of NOS during chronic hypoxia.

These results are in accordance with recent reports. Nitric oxide synthase protein has been detected by immunohistochemistry both in endothelium and smooth muscle of small, medium and large pulmonary vessels from rats with chronic hypoxic pulmonary hypertension, 
whereas, in normoxic animals, it is present only in the endothelium of large pulmonary vessels [21]. In the latter study, the monoclonal antibody, which detected the hypoxia-enhanced NO synthase, reacted both with the constitutive and inducible form. Nevertheless, the induction of NOS expression by hypoxia in pulmonary vascular smooth muscle, as well as activity assays used in this study showing an increase in the soluble NOS fraction, are consistent with an increase in iNOS. The same group and another subsequently reported increased mRNA and protein both for eNOS and iNOS in lungs from chronically hypoxic rats $[22,15]$.

In previous studies, we found that responses to the NO-mediated vasodilator substances, acetylcholine and calcium-ionophore A23187, are abolished in lungs from rats exposed to chronic normobaric hypoxia, but restored by pretreatment with $\mathrm{L}$-arginine $[3,23]$. Therefore, it is possible that, during chronic hypoxia, activity of NOS becomes downregulated, whereas that of iNOS is upregulated. The constitutive and inducible NOS activities have been shown to be inversely regulated by cytokines and/ or endotoxin [24]. Indeed, depressed endothelium-dependent vasodilation associated with evidence of increased NO production through induction of NOS has been observed previously. Incubation of rabbit aortic rings with interleukin-1 (IL-1) (100 U.mL $\left.\mathrm{mL}^{-1}\right)$ for $18 \mathrm{~h}$ leads to a loss of the relaxing response to acetylcholine in rings with endothelium, and a depressed contractile response to norepinephrine, which is restored by L-NMMA whether the endothelium is present or not [25]. Recent data, however, suggest increased expression of eNOS in lungs from chronically hypoxic rats [26].

The mechanisms leading to induction of NO synthase in the pulmonary vasculature during chronic hypoxia remain speculative. Induction of NOS in smooth muscle and endothelial cells may be caused by various cytokines [27, 28]. Cells of the vascular wall are not only influenced by cytokines but may also produce cytokines. Among these, IL-1 and interleukin-6 (IL-6) are released in the culture supernatant of endothelial cells exposed to hypoxia, and increases in mRNA for interleukin- $1 \alpha$ (IL-1 $\alpha$ ) and IL-6 have been demonstrated in the lungs of mice exposed to hypoxia $[29,30]$.

Whether increased NO production through induction of NO synthase plays a role in the physiological adaptation of the pulmonary circulation to chronic hypoxia remains open to question. In the present study, prolonged incubation was necessary to demonstrate increased NO release in the isolated pulmonary arteries and lungs from chronically hypoxic rats. Moreover, in rats exposed to chronic hypoxia, administration of NO synthesis inhibitors do not aggravate pulmonary hypertension and remodelling [31], whereas continuous inhalation of NO during exposure to chronic hypoxia protects against development of pulmonary hypertension [4]. Altogether these findings do not favour the hypothesis that increased production of nitric oxide during chronic hypoxia exerts an important role in attenuating the development of pulmonary hypertension.

\section{References}

1. Archer SL, Tolins JP, Raij L, Weir EK. Hypoxic pulmonary vasoconstriction is enhanced by inhibition of the synthesis of an endothelium derived relaxing factor. Biochem Biophys Res Commun 1989; 164: 1198-1205.

2. Liu S, Crawley DE, Barnes PJ, Evans TW. Endotheliumderived relaxing factor inhibits hypoxic pulmonary vasoconstriction in rats. Am Rev Respir Dis 1991; 143: 32-37.

3. Adnot S, Raffestin B, Eddahibi S, Braquet P, Chabrier PE. Loss of endothelium-dependent relaxant activity in the pulmonary circulation of rats exposed to chronic hypoxia. J Clin Invest 1991; 87: 155-162.

4. Kouyoumdjian C, Adnot S, Levame M, Eddahibi S, Bousbaa H, Raffestin B. Continuous inhalation of nitric oxide protects against development of pulmonary hypertension in chronically hypoxic rats. $J$ Clin Invest 1994; 94: 578-584.

5. Kourembanas S, McQuillan LP, Leung GK, Faller DV. Nitric oxide regulates the expression of vasoconstrictors and growth factors by vascular endothelium under both normoxia and hypoxia. J Clin Invest 1993; 92: 99104.

6. Tuder RM, Flook BE, Voelkel NF. Increased gene expression for VEGF and the VEGF receptors KDR/Flk and Flt in lungs exposed to acute and chronic hypoxia: modulation of gene expression by nitric oxide. J Clin Invest 1995; 95: 1798-1807.

7. Dinh-Xuan AT, Higenbottam TW, Colin A, et al. Impairment of endothelium-dependent pulmonary-artery relaxation in chronic obstructive lung disease. $N$ Engl J Med 1991; 324: 1539-1547.

8. Carville C, Raffestin B, Eddahibi S, Blouquit Y, Adnot $\mathrm{S}$. Loss of endothelium-dependent relaxation of large pulmonary arteries from rats exposed to chronic hypoxia: effects of in vitro and in vivo supplementation with Larginine. J Cardiovasc Pharmacol 1993; 22: 889-896.

9. Rodman DM. Chronic hypoxia selectively augments rat pulmonary artery $\mathrm{Ca}^{2+}$ and $\mathrm{K}^{+}$channel-mediated relaxation. Am J Physiol 1992; 263 (Lung Cell Mol Physiol 7): L88-L94.

10. Resta TC, Walker BR. Chronic hypoxia selectively augments endothelium-dependent pulmonary arterial vasodilation. Am J Physiol 1996; 270 (Heart Circ Physiol 39): H888-H896.

11. Isaacson TC, Hampl V, Weir EK, Nelson DP, Archer SL. Increased endothelium-derived NO in hypertensive pulmonary circulation of chronically hypoxic rats. J Appl Physiol 1994; 76: 933-940.

12. Barer G, Emery CJ, Stewart A, Bee D, Howard P. Endothelial control of the pulmonary circulation in normal and chronically hypoxic rats. J Physiol (Lond) 1993; 463: $1-16$.

13. Oka M, Hasunuma K, Webb S, Stelzner TJ, Rodman DM, McMurtry IF. EDRF suppresses an unidentified vasoconstrictor mechanism in hypertensive rat lungs. Am J Physiol 1993; 264 (Lung Cell Mol Physiol 8): L587-L597.

14. Moncada S, Palmer RMJ, Higgs EA. Nitric oxide physiology, pathophysiology, and pharmacology. Pharmacol Rev 1991; 43: 109-142.

15. Le Cras TD, Xue C, Rengasamy A, Johns RA. Endothelial NO synthase mRNA and protein, and inducible NO synthase mRNA are upregulated in the rat lung following chronic hypoxia. Am J Physiol 1996; 270 (Lung Cell Mol Physiol 14): L164-L170.

16. Schini VB, Vanhoutte PM. Inhibitors of calmodulin impair the constitutive but not the inducible nitric oxide synthase activity in the rat aorta. J Pharmacol Exp Ther 1992; 261: 553-559.

17. Chomczynski P, Sacchi N. Single step method of RNA 
isolation by acid guanidinium thiocyanate-phenol-chloroform extraction. Anal Biochem 1987; 162: 156-159.

18. Nunokawa Y, Ishida N, Tanaka S. Cloning of inducible nitric oxide synthase in rat vascular smooth muscle cells. Biochem Biophys Res Commun 1993; 191: 89-94.

19. Griffiths MJD, Liu S, Curzen NP, Messent M, Evans TW. In vivo treatment with endotoxin induces nitric oxide synthase in rat main pulmonary artery. Am $J$ Physiol 1995; 268 (Lung Cell Mol Physiol 12): L509-518.

20. Schott CA, Gray GA, Stoclet JC. Dependence of endotoxin-induced vascular hyporeactivity on extracellular L-arginine. Br J Pharmacol 1993; 108: 38-43.

21. Xue C, Rengasamy A, Le Cras TD, Koberna PA, Dailey GC, Johns RA. Distribution of NOS in normoxic vs hypoxic rat lung: upregulation of NOS by chronic hypoxia. Am J Physiol 1994; 267 (Lung Cell Mol Physiol 11): L667-L678.

22. Kasahara Y, Tatsumi K, Nakano $\mathrm{H}$, et al. The induction of inducible nitric oxide synthase in rat lungs with pulmonary hypertension. Am J Respir Crit Care Med 1995; 151: A728.

23. Eddahibi S, Adnot S, Carville C, Blouquit Y, Raffestin B. L-arginine restores endothelium-dependent relaxation in pulmonary circulation of chronically hypoxic rats. $\mathrm{Am}$ J Physiol 1992; 263 (Lung Cell Mol Physiol 7): L194L200.

24. Salter M, Knowles RG, Moncada S. Widespread tissue distribution, species distribution and changes in activity of $\mathrm{Ca}^{2+}$-dependent and $\mathrm{Ca}^{2+}$-independent nitric oxide synthases. FEBS Lett 1991; 291: 145-149.

25. Robert R, Chapelain B, Jean T, Néliat G. Interleukin-1 impairs both vascular contraction and relaxation in rabbit isolated aorta. Biochem Biophys Res Commun 1992; 182: 733-738.

26. Shaul PW, North AJ, Brannon TS, et al. Prolonged in vivo hypoxia enhances nitric oxide synthase type I and type III gene expression in adult rat lung. Am J Respir Cell Mol Biol 1995; 13: 167-174.

27. Junquero DC, Schini VB, Scott-Burden T, Vanhoutte PM. Transforming growth factor- $\beta_{1}$ inhibits L-arginine-derived relaxing factor(s) from smooth muscle. Am J Physiol 1992; 262 (Heart Circ Physiol 31): H1788-H1795.

28. Kanno K, Hirata Y, Imai T, Marumo F. Induction of nitric oxide synthase gene by interleukin in vascular smooth muscle cells. Hypertension 1993; 22: 34-39.

29. Shreeniwas R, Koga S, Karakurum M, et al. Hypoxiamediated induction of endothelial cell interleukin- $1_{\alpha} . J$ Clin Invest 1992; 90: 2333-2339.

30. Yan SF, Tritto I, Pinsky D, et al. Induction of interleukin-6 (IL-6) by hypoxia in vascular cells: central role of the binding site for nuclear factor-IL-6. J Biol Chem 1995; 270: 11463-11471.

31. Hampl V, Archer SL, Nelson DP, Weir EK. Chronic EDRF inhibition and hypoxia: effects on pulmonary circulation and systemic blood pressure. J Appl Physiol 1993; 75: 1748-1757. 